
Military Technical College Kobry El-Kobbah, Cairo, Egypt.

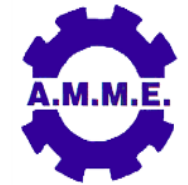

$18^{\text {th }}$ International Conference on Applied Mechanics and Mechanical Engineering.

\title{
ASSESSMENT OF AIR DIFFUSION PERFORMANCE INDEX IN A SURGICAL OPERATING ROOM BY COMPUTATIONAL FLUID DYNAMICS TECHNIQUE
}

\author{
A. M. Alabasiry ${ }^{1}$, E. Elgendy ${ }^{2}$, K. Elsayed ${ }^{3}$ and M. Fatouh ${ }^{4}$
}

\begin{abstract}
Surgical operating room needs an efficient ventilation system to achieve thermal comfort and clean environment. This paper aims to improve the air distribution in the operating rooms with two operating tables configuration. Six test cases with different numbers, sizes and locations of exhaust air grills have been simulated using CFD and validated with experimental measurements. The air diffusion performance index (ADPI) value has been estimated for each case. The results show that the case with eight exhaust air grills distributed in the four corners of the operating room gives the highest ADPI (63.06\%).
\end{abstract}

\section{KEYWORDS}

Operating Room, Air Diffusion Performance Index (ADPI), Computational Fluid Dynamics (CFD), Effective Draft Temperature.

Post graduate student, Mechanical Power Engineering Department, Faculty of Engineering, Helwan University, Cairo, Egypt. Email:Anas_alabasiry@yahoo.com.

2 Associate professor, Mechanical Power Engineering Department, Faculty of Engineering, Helwan University, Cairo, Egypt. Email: elgenady@hotmail.com

3 Assistant professor, Mechanical Power Engineering Department, Faculty of Engineering, Helwan University, Cairo, Egypt. Email: kelsayed75@gmail.com

4 Professor, Mechanical Power Engineering Department, Faculty of Engineering, Helwan University, Cairo, Egypt. Dean of Faculty. Email: drmohfat@hotmail.com 


\section{INTRODUCTION}

The importance of air distribution in operating rooms and effective indoor air diffusion is essential to achieve good thermal comfort as well as to minimize the energy consumption. Air Diffusion Performance Index (ADPI) is defined by the American Society of Heating, Refrigerating, and Air-Conditioning Engineers (ASHRAE) Standard 113 [1] as the percentage of points measured in a room that is within both the ASHRAE temperature and velocity ranges for comfort. ADPI is based on the acceptance and recognition that it is not possible to achieve a comfortable level of 100 percent, but 70 percent acceptance is achievable and measurable. For an office environment in the cooling mode, for example, designers should plan to have an ADPI of greater than 80 .

\section{Literature Review}

The literature has many investigations on air diffusion in surgical operating room. Chow et al. [1] reviewed research activities and practical guidance regarding ventilation performance in operating theatres against airborne infection by conducting experimental tests as well as CFD simulation. Their results confirmed that the turbulent airflow increases the effectiveness of air exchange and distribution but speeds up the microbial dispersion. On the other hand, low-velocity unidirectional flow tends to minimize the spread of airborne contaminants and directed them towards the exhaust outlets.

Chow et al. [2] studied the performance of the ventilation system in a non-standard operating room. They simulated the temperature distribution, airflow pattern and the contaminant dispersion using two cases of lightening positions. They made field measured data to support the development of the inlet/outlet boundary conditions to examine the thermal comfort level, and the possible effects of the microbiological particles released by the surgical team on the patient and at the wound site of the patient on the surgical team. They used CFD analysis supported by field measurements and found that the level of thermal comfort for the studied conditions in the entire room is satisfactory and the airflow scheme at the operation area has been disturbed.

Woloszynet al. [3] studied a different air distribution system (diagonal air distribution system) for a hospital operating room. They analyzed the air quality inside a room with the numerical CFD simulation software as well as implementing an experimental study. They reported that the contaminant distribution depended strongly on the presence of obstacles such as medical equipment and staff. The distribution of the contaminant in an operating room, and therefore the risk to patients, depends on the geometrical parameters of the room, such as the position of the air inlet and outlet, the contaminant source, and objects that could perturb the airflow.

Chow et al. [4] computationally investigated the ventilation performance in a hospital negative-pressure operating theater in relation to different combinations of medical lamp configurations and modes of launching infectious particles into the room air. They stated that the air flow performance in the negative pressure operating theater was satisfactory and comparable to the original positive pressure design. 
Brohus et al. [5] investigated the influence of movements on contaminant transport in an operating room during an orthopedic surgical operation. They used smoke visualization and computational fluid dynamics (CFD). The results confirmed that the influence of movements might cause a local but serious risk of transport of bacteria from the non-clean zone to the clean zone.

Ho et al. [6] numerically analyzed a hospital operating room thermal comfort and contaminant removal by three-dimensional analysis. They used an arrangement of operating room with cold clean air is supplied to the room through high sidewall grilles and exhausted through low sidewall grilles on the opposite wall. They calculated the predicted mean vote (PMV) and the contaminant removal effectiveness (CRE) to assess the ventilation performance and thermal comfort of the room. They came to the result that an overall better performance can be achieved by placing the supply grilles closer to the vertical centerline of the wall while the location of the exhaust grilles is somewhat insignificant.

Loomansa et al. [7] assessed the performance of an operating theatre design using CFD simulation and tracer gas measurements in a hospital operating room. They studied the efficiency of a ventilation system in an operating theatre to provide an objective performance-based methodology for the assessment of (innovative) ventilation designs for operating theatres. They conducted experimental and computational investigation. They found that the assessment methodology functions and that the innovative down-flow systems have a direct relation with the surgical site infection rate.

Balocco [8] investigated the hospital ventilation system in case of potential exposure to contaminants in an actual hospitalization isolation room for immune suppressed or infectious patients. The efficiency of the existing heating, ventilation and air conditioning (HVAC) (airflow patterns, distribution and velocity, and the articulate dispersion) inside an existing typical hospitalization room equipped with an HVAC, with variable air volume (VAV) primary air system, combined with a ceiling radiant panel have been investigated. The study provides useful indications for controlling dispersion and concentration zones of droplet nuclei, recommendations for disease control and careful design and optimization of ventilation, significant reduction of energy consumption. The best type and position of the high inlet air diffuser, best mean air velocity at the patients' beds, less than $0.25 \mathrm{~m} / \mathrm{s}$, best position of the extract air diffuser that should be at low levels.

Lydon et al. [9] computationally studied the ultra-clean ventilation (UCV) system performance relating to airborne infections in operating theatres. They investigated the effects of the opening and closing of doors in two pressurization scenarios ( 0 and $20 \mathrm{~Pa}$ ). They came to the fact that the UCV system operates effectively in the positive pressure $(20 \mathrm{~Pa})$ scenario but fails when there is no pressure difference between the operating theatre and surrounding areas. They required more sophisticated turbulence models, such as the large eddy simulation model (LES), to investigate the more complex fluid interactions inside the protective air barrier and the effects of human activity on contaminant transport.

Balocco et al. [10] conducted a numerical investigation of different airflow schemes in a real hospital orthopedic operating room. They investigated which scheme of the ventilation system inside the operating theater (OT). They come to the fact that the 
closer to the center of the room and larger surface of the air supply diffusers connected with the position of the return grilles, the better the air flow performance when provided both by unidirectional vertical and horizontal air flows, especially if the use of air curtains mainly located at the ceiling is considered.

Liu et al [11] conducted a numerical study of airborne particle transport in a hospital operating room by studying and controlling of airborne particles in an operating zone above the surgical table in an operating room using CFD. They found that the optimum design from a series of available choices, such as design of air supply canopy, air exit location, operating table arrangement, as well as the disturbance of the flow field by different lamps. They proofed that the particle source location, air (supply) inlet design, operating table location, and lamp design is among the critical parameters responsible for the particle distribution within the operating room.

\section{Aim of the Present Work}

So far, a large amount of studies has been done for air diffusion and thermal comfort in occupied spaces. However, among these studies, relatively limited investigations were devoted to surgical operating rooms with double operating tables and surgical teams (double patient operating room). Considering the need of using it in some special operations, it is significant to focus on such kind of operating room.

The aim of the present study is to improve the air distribution in an operating room with two operating tables' configurations. To achieve that the present study aims to investigate the effect of the number and location of the exhaust air grills on the ADPI to determine the best case for air diffusion in the double patient operating room.

\section{MODELING AND COMPUTATIONAL DETAILS}

\section{Geometry}

The geometry is based on a real existing surgical operating room in 6th of October, Giza, Egypt as shown in Fig. 1. Room dimension of $7.5 \mathrm{~m}$ length $\times 7.4 \mathrm{~m}$ width $\times 3 \mathrm{~m}$ height containing six supply air diffusers $(0.6 \mathrm{~m} \times 0.6 \mathrm{~m})$ each at the center of the ceiling of the room and fourteen ceiling lambs with the same dimensions (fixed with all cases). The exhaust air grills located in the corners of the room and their number, sizes and locations have been changed in each case. The geometry contains also two patient tables with six standing persons at each table representing surgical staff as well as two laying persons on tables as patients. Two equipment devices are located behind tables.

In this study six different test cases have been studied as shown in Fig. 2. As shown in the Fig. 2 flow velocity on grill face has been remained constant at $2 \mathrm{~m} / \mathrm{s}$ as per manufacturer recommendations to maintain suitable sound level and reduce pressure drop on the grill. Selection report for the exhaust air grills containing all data of sound criteria according to ASHRAE standard for accepted sound limits inside surgical operating rooms and sizing selection has been prepared. The different areas or sizes of the grill changed in accordance to number of grills in each grill which sound logic given that $Q=A \times V$ when $V$ (velocity) is constant in all cases and $Q$ 
(flow rate) changed according to changing number of grills then $\mathrm{A}$ (area) must change without changing face velocity

\section{Mesh}

The grid has been generated as show in Fig. 3 using Ansys meshing with tetrahadron type elements with about 1 million elements.

\section{Computational Settings}

The working fluid is air and treated as incompressible gas with constant density $(\rho)=$ $1.225 \mathrm{~kg} / \mathrm{m}^{\mathrm{a}}$ and dynamic viscosity $(\mu)=1.789 \mathrm{~kg} / \mathrm{ms}$. The inlet velocity was 0.39 $\mathrm{m} / \mathrm{s}$ and hydraulic diameter was calculated on the inlet diffuser cross sectional area of $0.6 \times 0.6 \mathrm{~m}^{2}$, so Reynolds number has been calculated to determine whether the flow is laminar or turbulent (Reynolds number $=16142.56 \geq 4000$ then the flow is turbulent). Using the standard $k-\varepsilon$ turbulence modeling with standard wall function. The pressure-velocity coupling was SIMPLEC and the other spatial discretization settings were least square cell based for gradient, second order for the pressure, second order upwind for the momentum, second order upwind for the turbulent kinetic energy, second order upwind for the turbulent dissipation rate.

\section{Boundary Conditions}

The equipment represents devices located in the operating room and considered as stationary wall with no-slip shear condition and its thermal conditions selected as a heat flux of $100 \frac{w^{2}}{m}$ [13]. The supply air grills are set as velocity inlet with velocity magnitude of $0.393 \mathrm{~m} / \mathrm{s}$ each and inlet air temperature of $16^{\circ} \mathrm{C}$ as designed. The exhaust air grills are considered as outflow and its flow rate weighting varies with every case according to number of grills.

The lights are considered as stationary wall with no-slip shear condition and its thermal conditions selected as a heat flux of $215 \mathrm{w} / \mathrm{m}^{2}$ each as exist in the room used in experimental validation. All persons represent the surgical crew for each table and patients and considered as stationary wall with no-slip shear condition and its thermal conditions selected temperature of $34^{\circ} \mathrm{C}$.

\section{Mesh Independent Study}

The mesh independent study showed that increasing the cell size did not change the temperature profile as shown in Fig. 4 and Table 1. A center line was taken in the room to investigate mesh independent study at $z=1.3 \mathrm{~m}, y=0: 7.4 \mathrm{~m}, \mathrm{x}=3.75 \mathrm{~m}$. 384 values of velocity as well as temperature have been recorded along this line for each mesh size and the average of each size was used in Table 1 to calculate the percentage difference between mesh sizes. Consequently, the medium mesh of each case will be used for all subsequent analysis to reduce computational cost. 


\section{Validation of the CFD Results Using a Single Surgical Table OT}

In this study a real single table operating room has been used for the validation of the computational study. The Six of October hospital in Giza, Egypt has a full size operating room with all required equipment and devices. The room dimensions are $7.5 \times 7.4 \times 3 \mathrm{~m}^{3}$ as shown in Fig. 5. The operating room has six ceiling perforated type supply air diffusers each is $0.6 \mathrm{~m} \times 0.6 \mathrm{~m}^{2}$ and eight exhaust air grills distributed in the four corners of the room at high and low positions.

The experiments are conducted by measuring the temperature at specified points in the room and comparing the experimental results with the temperature results obtained from numerical modeling (cf. Fig. 6) using ANSYS-Fluent commercial package at the same points.

The points were selected at a certain line across the room $z=1.3 \mathrm{~m}, y=0: 7.4 \mathrm{~m}, \mathrm{x}=$ $3.75 \mathrm{~m}$. At steady state condition using about 18 points for comparison. The measuring was performed by using a hand-held temperature sensor tested and calibrated (CEM digital thermo-hygrometer, model DT-8820, resolution $0.1^{\circ} \mathrm{C}$ for temperature).

The resulting temperature values from ANSYS modeling indicated a relatively matching with experimental results at the same positions as indicated in Fig.6. Therefore, ANSYS can be used to modeling and generating CFD for the required research.

\section{RESULTS AND DISCUSSIONS}

The present study investigated six schemes of the exhaust air grills each one has changed in sizes, numbers and locations as illustrated in Fig.2. Around 400 iterations have been calculated in each case until convergence has been achieved as well as checking residuals to be less than $10^{-5}$ and ensure the continuity of mass flux by calculating inlets and exits flow. Then calculate the effective draft temperature.

Effective draft temperature is defined by ASHRAE standard 113 [12] as a calculated temperature difference that combines air temperature difference and measured air speed at each test points and can be calculated as follow:

$$
\phi_{n}=t_{a c n}-t_{a c}-8.0\left(v_{a n}-0.15\right)
$$

where

$\phi_{n} \quad=\quad$ effective draft temperature at test point $n(k)$

$t_{\text {acn }}=\quad$ corrected temperature at test point $n\left({ }^{\circ} \mathrm{C}\right)$

$t_{a c}=$ average test zone temperature $\left({ }^{\circ} \mathrm{C}\right)$

$v_{a n}=$ time-averaged speed at test point $n(\mathrm{~m} / \mathrm{s})$

Three levels $(Z=1.2-1.4-1.6 \mathrm{~m})$ were considered for about 100 points in each level and then extracting the results to excel sheet to know the percentage of acceptable 
effective draft temperature values to all temperature values for all point in each level to calculate ADPI for every case.

Researches indicate that a high percentage of people are comfortable when the

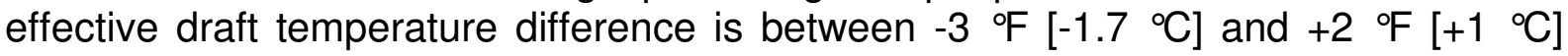
(ASHRAE) Standard 113 [1]. So, we will take this range as criteria for ADPI

$$
A D P I=\frac{\text { Number of test points that meet criteria }}{\text { Total number of test points }} \%
$$

Figure 7 depicts the effective draft temperature for the six schemes at $z=1.6 \mathrm{~m}$ from the floor. Table 2 lists the calculated ADPI for all schemes at the three levels.

As shown in Fig. 7 each case has a different contour for ADPI results. By the fact that in all cases the supply air diffusers are fixed in the same positions and with the same air quantity and velocity, these differences are mainly due to changing the direction of air movement towards the exhaust air grills.

In each case, various positions of exhaust air grills forced the air to move in different streams which change the air velocity and temperature at the tested points. As a function of air velocity and temperature, ADPI values changed with every case giving criteria for evaluating the performance of air distribution system for each case.

The results (as shown in Table 2) indicated that the worst ADPI value are with case 4 at $1.2 \mathrm{~m}(38.5 \%)$ and that sounds logic because in this case only 4 exhaust air grills located at low level with no exhaust grills at elevated level which force air to go downward quickly before spreading in the room far away from the level of the standing people, that makes a lot of points inside the room out of desired temperature and air velocity. Even with various levels of testing this case gives the lowest ADPI value in average (41\%). The second lowest case in ADPI value is case 5 $(45.49 \%)$ especially at $1.2 \mathrm{mwhere}$ the supply air does not have enough time to reach the lower level. In this case, there are only two exhaust air grills at the elevated level. Cases 2,3 and 6 are relatively better in ADPI values due to better air distribution.

The best case in ADPI value is case 1 (63.06\%). In this configuration eight exhaust air grills are uniformly distributed at high and low levels in the four corners of the room. This enables the supply air to fill the room with uniform velocity and temperature and reduces the air stagnant areas. The amount of air exhausted from the lower level is twice the amount exhausted from the higher level for bacterial dispersion elimination reasons.

\section{CONCLUSIONS}

The paper investigated the air distribution in a surgical operating room to evaluate six cases of exhaust air grills from the ADPI value point of view. The results reached the fact that case 1 which has 8 exhaust air grills distributed in four corners of the room at high and low levels is the best layout for the exhaust air grill with ADPI percentage of $58.2 \%$ at $\mathrm{z}=1.2 \mathrm{~m}, 61.86 \%$ at $\mathrm{z}=1.4 \mathrm{~m}$ and $69.07 \%$ at $\mathrm{z}=1.6 \mathrm{~m}$. Other cases indicated lower values of ADPI at each level because of the non-uniform distribution 
of the exhaust air grills in the room which forces the supply air to move towards their directionsand prevent it from reaching the unoccupied corners.

\section{REFERENCES}

[1] Chow, Tin-Tai, and Xiao-Yu Yang. "Ventilation performance in operating theatres against airborne infection: review of research activities and practical guidance", Journal of Hospital Infection 56.2 (2004): 85-92.

[2] Chow, Tin-Tai, and Xiao-Yu Yang. "Performance of ventilation system in a nonstandard operating room", Building and environment 38.12 (2003): 1401-1411.

[3] Woloszyn, Monika, Joseph Virgone, and Stéphane Melen. "Diagonal airdistribution system for operating rooms: experiment and modeling", Building and Environment 39.10 (2004): 1171-1178.

[4] Chow, Tin-tai, Anne Kwan, Zhang Lin, and Wei Bai, "A Computer Evaluation of Ventilation Performance in a Negative-Pressure Operating Theater", Anesthesia \& Analgesia 103, no. 4 (2006): 913-918.

[5] Brohus, H., K. D. Balling, and D. Jeppesen. "Influence of movements on contaminant transport in an operating room", Indoor air 16.5 (2006): 356-372.

[6] Ho, Son H., Luis Rosario, and Muhammad M. Rahman. "Three-dimensional analysis for hospital operating room thermal comfort and contaminant removal", Applied Thermal Engineering 29.10 (2009): 2080-2092.

[7] Loomans, M. G. L. C., W. Van Houdt, A. D. Lemaire, and J. L. M. Hensen. "Performance assessment of an operating theatre design using CFD simulation and tracer gas measurements", Indoor and Built Environment 17, no. 4 (2008): 299-312.

[8] Balocco, Carla. "Hospital ventilation simulation for the study of potential exposure to contaminants", Building Simulation. Vol. 4. No. 1. Tsinghua Press, 2011.

[9] Lydon, Gearoid P., Derek B. Ingham, and Monjur M. Mourshed. "Ultra clean ventilation system performance relating to airborne infections in operating theatres using CFD modeling", Build Simul 7.3 (2014): 277-287.

[10] Balocco, Carla, Giuseppe Petrone, and Giuliano Cammarata. "Numerical investigation of different airflow schemes in a real operating theatre", Journal of Biomedical Science and Engineering 8.02 (2015): 73.

[11] Liu, Yunlong, Alfred Moser, and Kazuyoshi Harimoto. "Numerical study of airborne particle transport in an operating room", International Journal of Ventilation 2.2 (2003): 103-110.

[12] ANSI/ASHRAE standard 113-2005 "Method of Testing for room air diffusion".

[13] ASHRAE HVAC Design Manual for Hospitals and Clinics (Second Edition).

[14] Elsayed Kh.,"Design of a novel gas cyclone vortex finder using the adjoint method", Separation and Purification Technology,142,(2015): 274-286. 


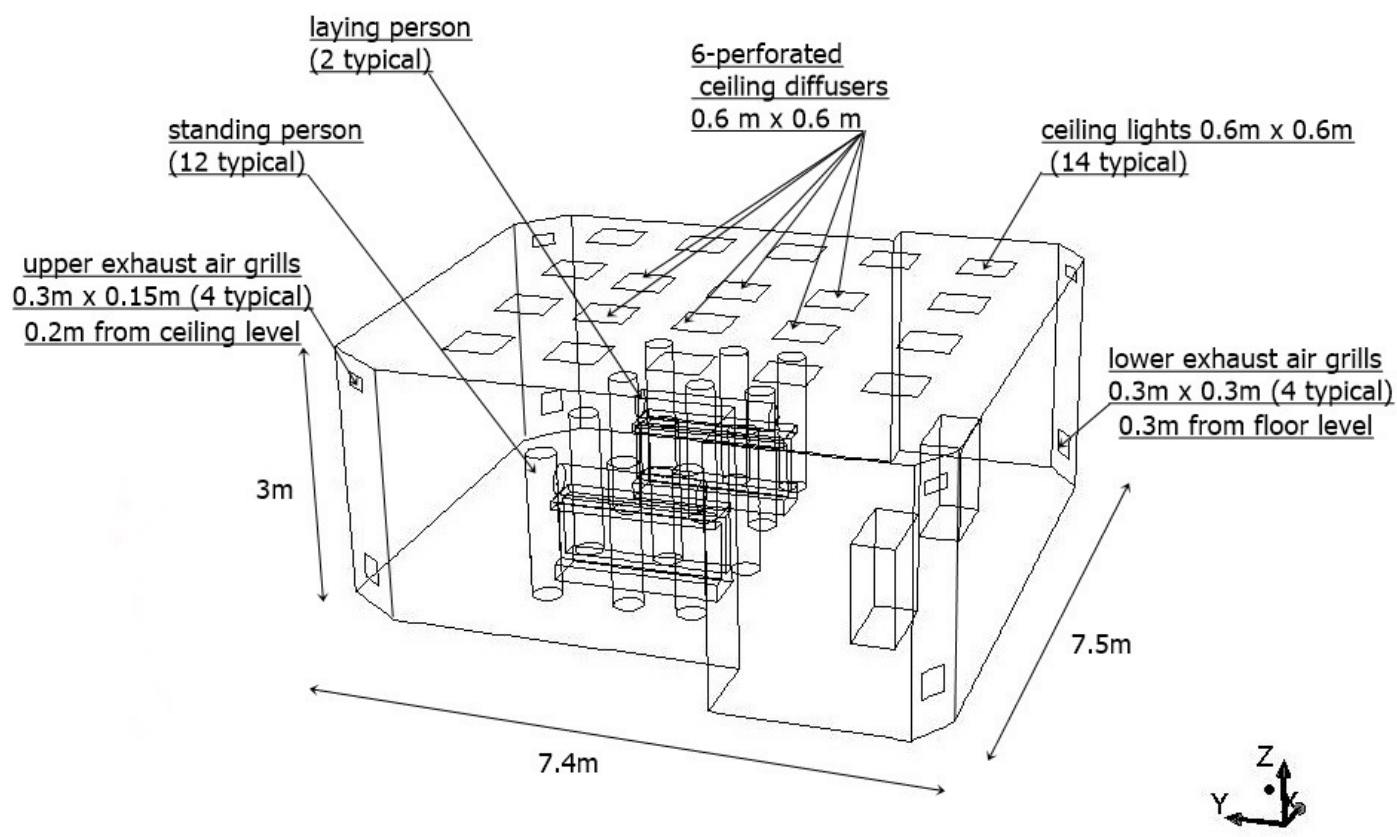

Fig. 1. Operating room geometry.

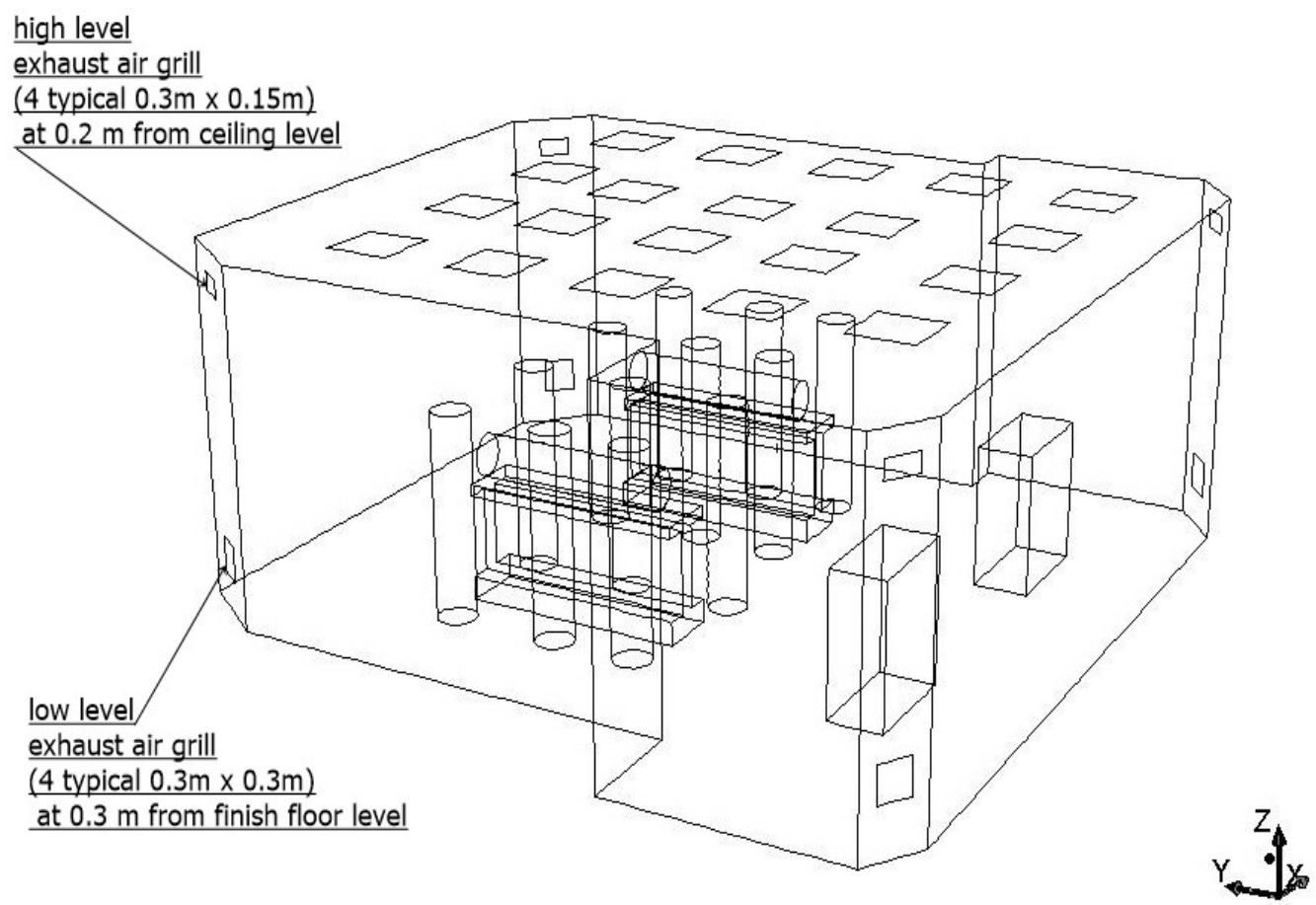

(a) Case 1: Eight exhaust air grills in the four corners at high and low levels.

Fig. 2. The geometry of the tested cases. 
high level

exhaust air grill

(2 typical $0.3 \mathrm{~m} \times 0.3 \mathrm{~m}$

at $0.2 \mathrm{~m}$ from ceiling level

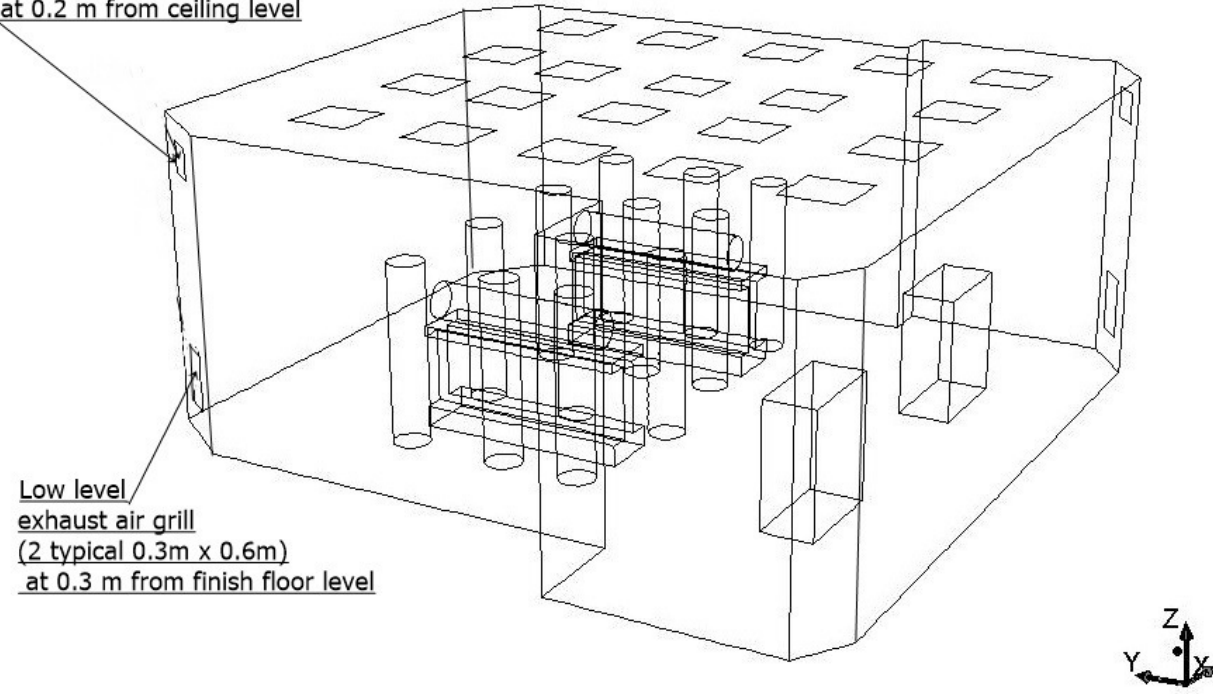

(b) Case 2: Four exhaust air grills in two corners at high and low levels with bigger sizes to maintain air velocity of $2 \mathrm{~m} / \mathrm{s}$.

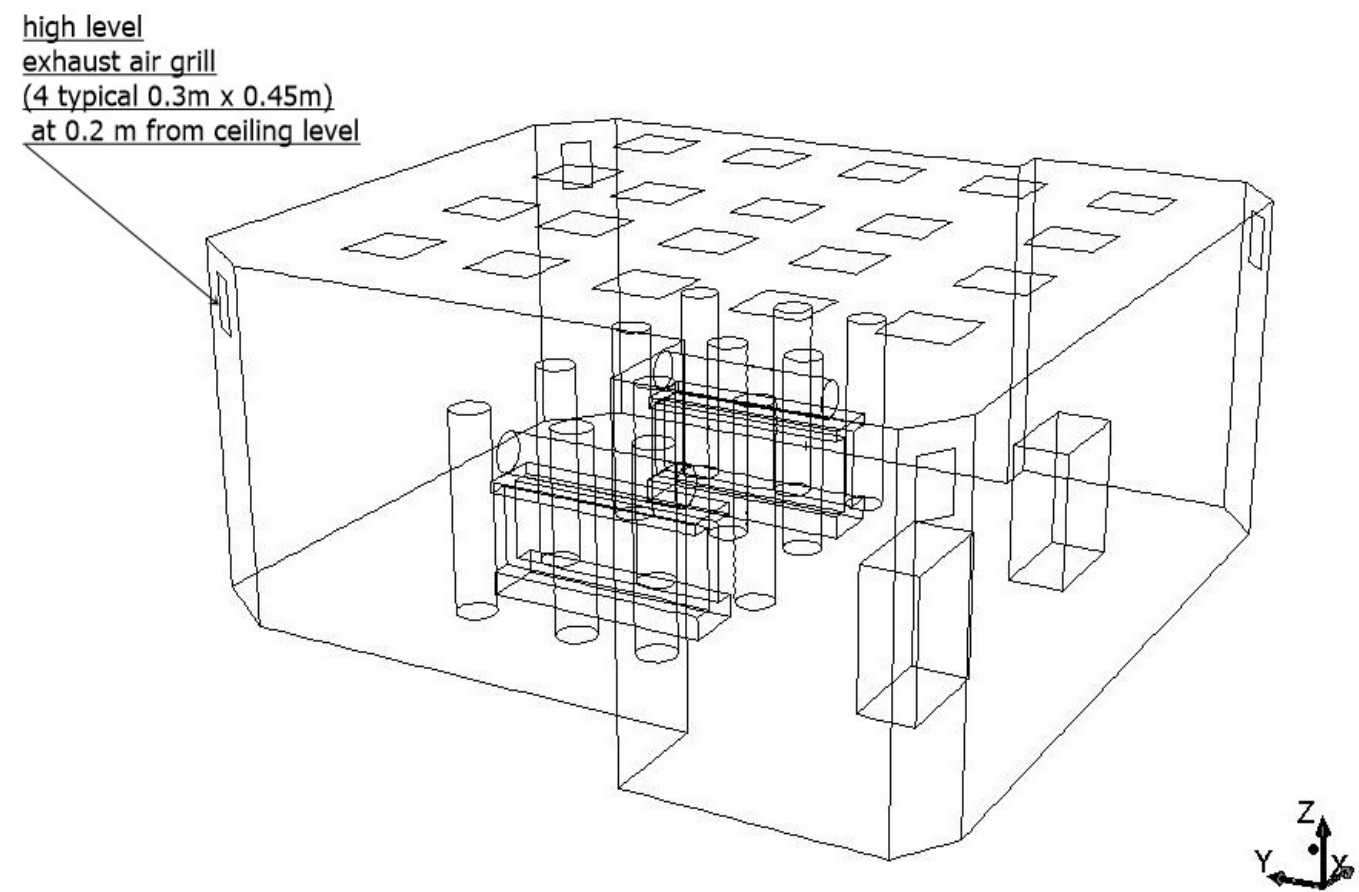

(c) Case 3: Four exhaust air grills in four corners at elevated level with bigger sizes to maintain air velocity of $2 \mathrm{~m} / \mathrm{s}$.

Fig. 2. The geometry of the tested cases (Continued). 


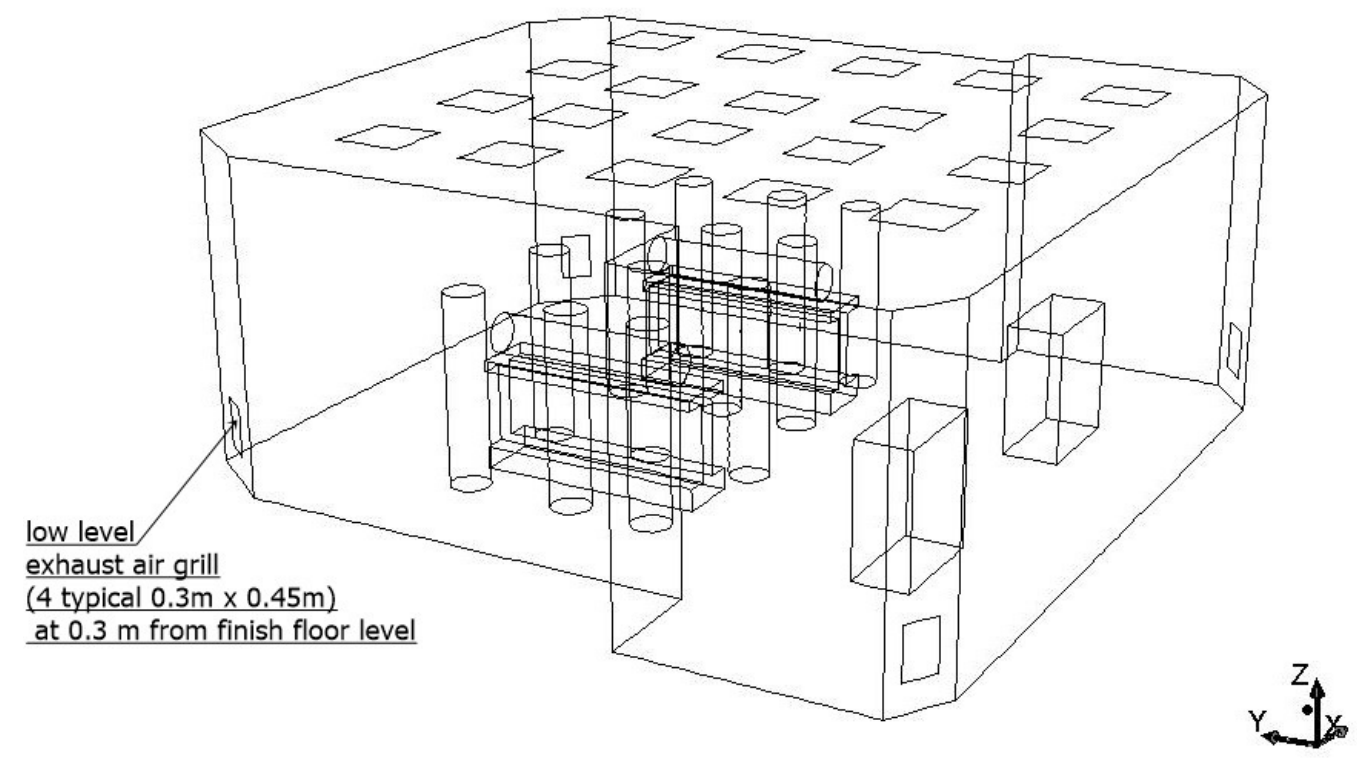

(d) Case 4: Four exhaust air grills in four corners at low level with the same sizes as case 3.

high level

exhaust air grill

( 2 typical $0.6 \mathrm{~m} \times 0.45 \mathrm{~m}$ )

at $0.2 \mathrm{~m}$ from ceiling level

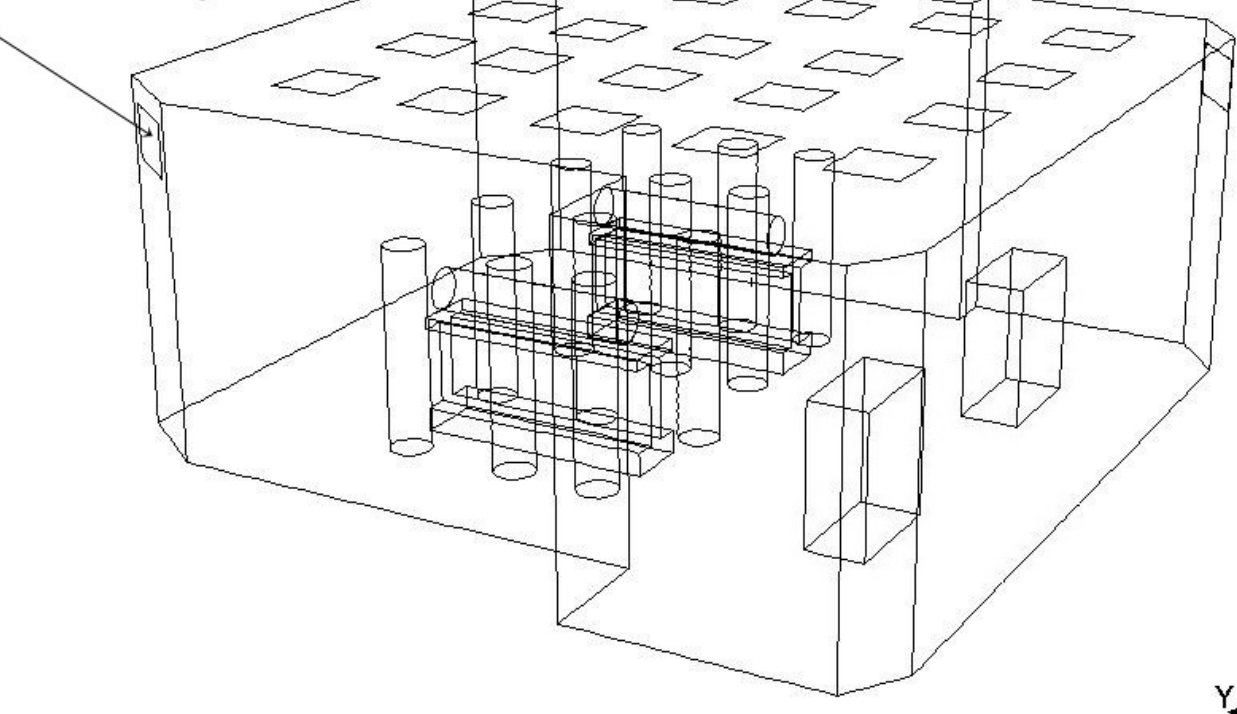

(e) Case 5: Two exhaust air grills in two corners at elevated level with bigger sizes to maintain air velocity of $2 \mathrm{~m} / \mathrm{s}$.

Fig. 2. The geometry of the tested cases (continued). 


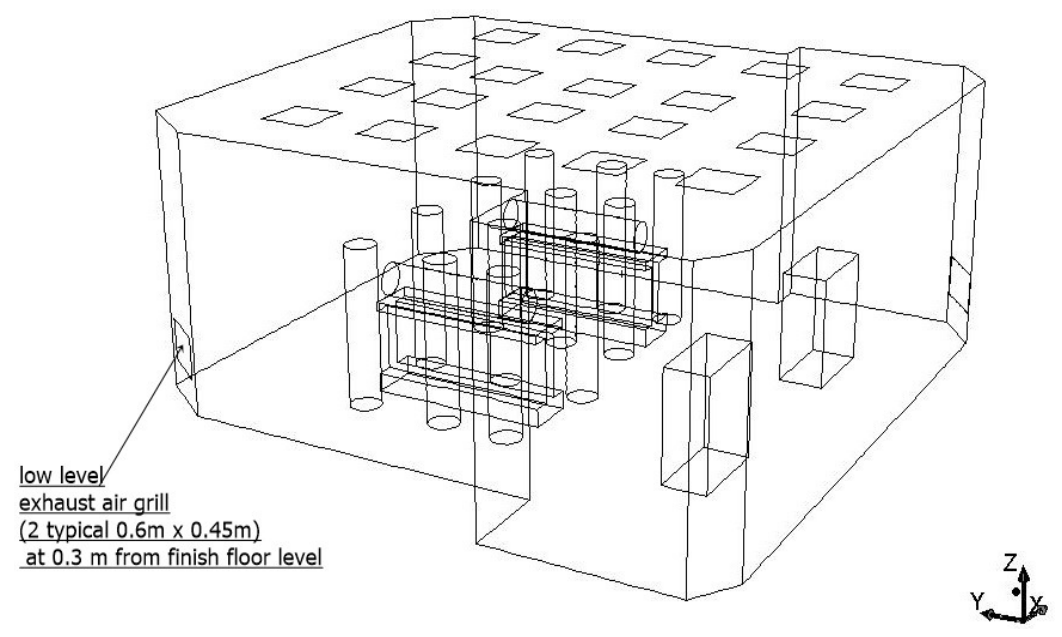

(f) Case 6: Two exhaust air grills in two corners at low level with the same sizes as case 5.

Fig. 2. The geometry of the tested cases (continued).

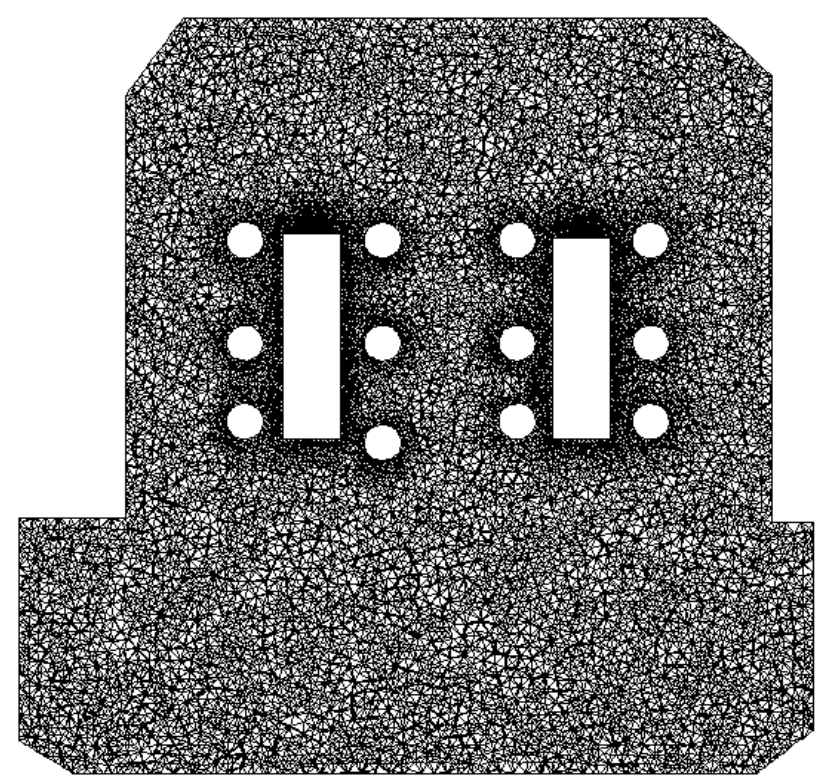

Fig. 3 (a): XY section in the used mesh (Tetra-hadron type elements - 1 million elements).

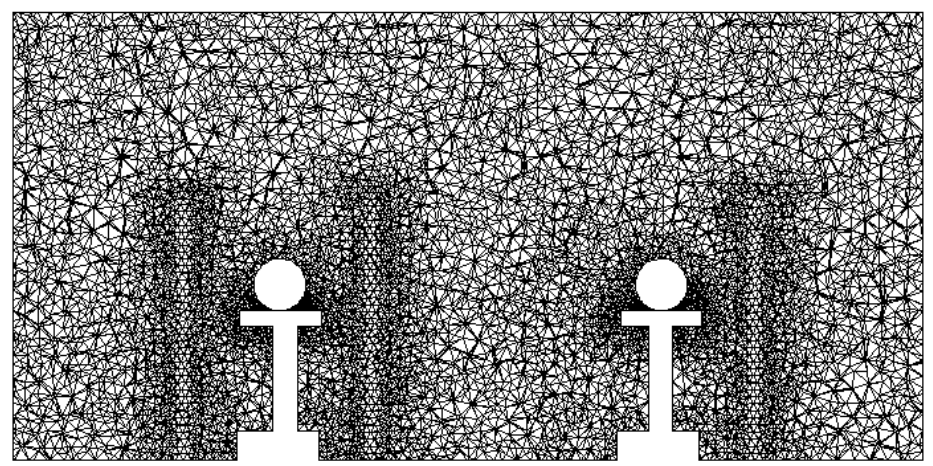

Fig. 3 (b): XZ section in the used mesh (Tetra-hadron type elements - 1 million elements). 


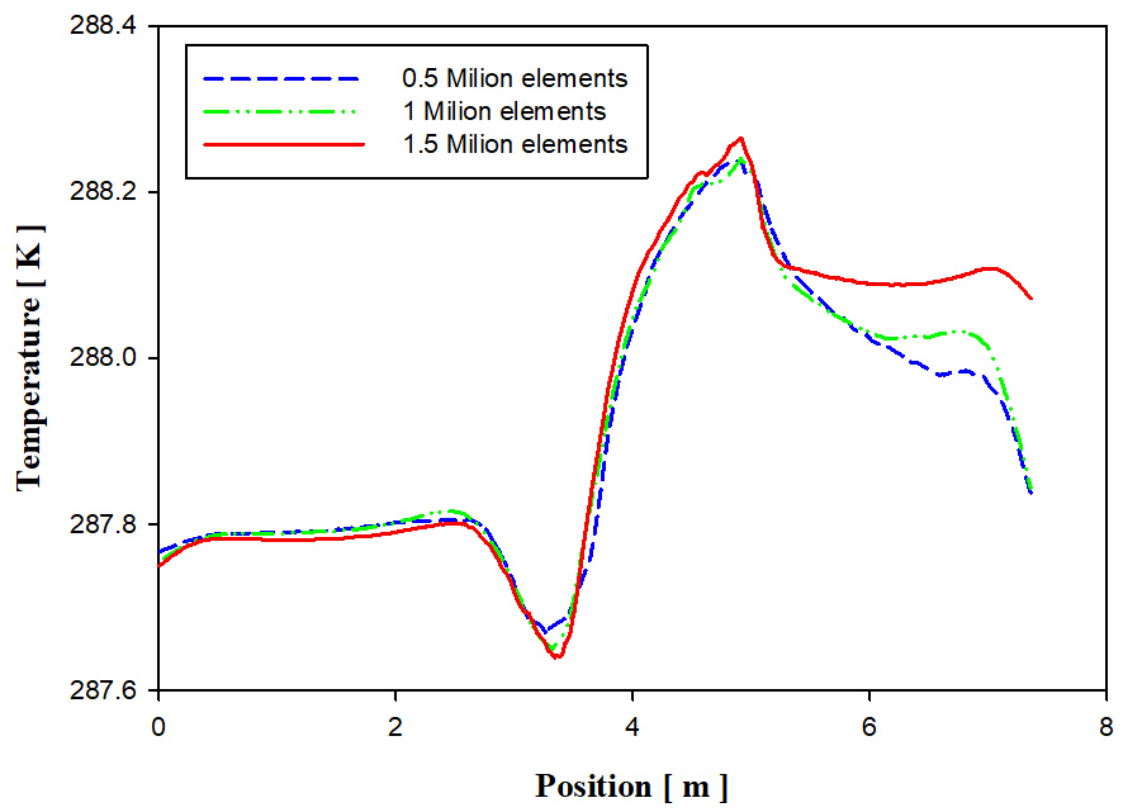

Fig. 4. The temperature profile for different mesh sizes.

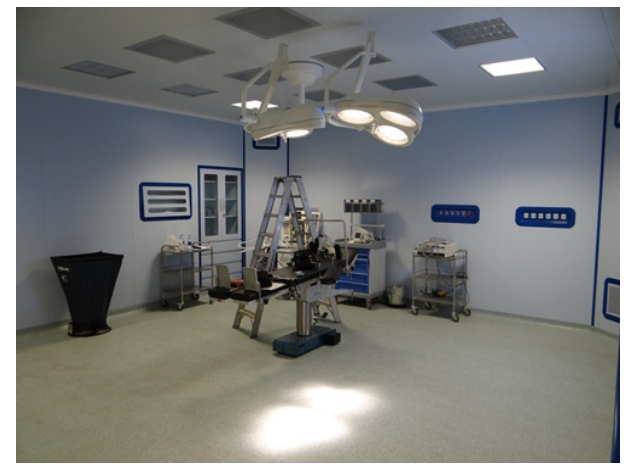

(a) A photograph

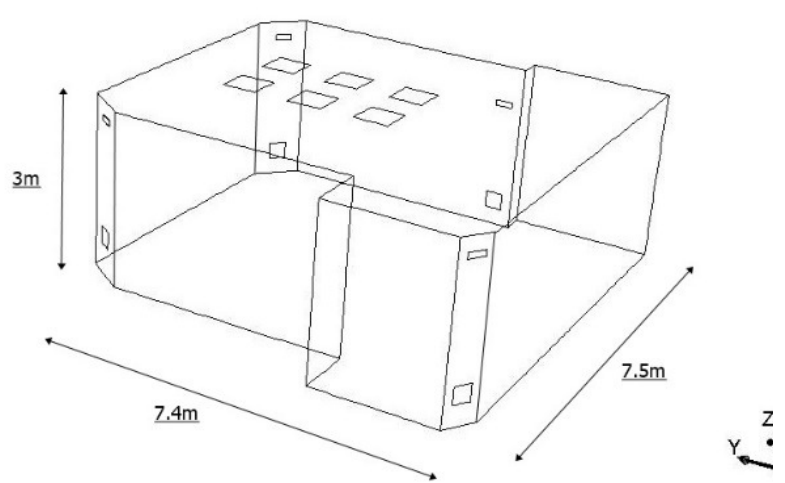

(b) The main dimensions

Fig. 5. The tested operating room for validation.

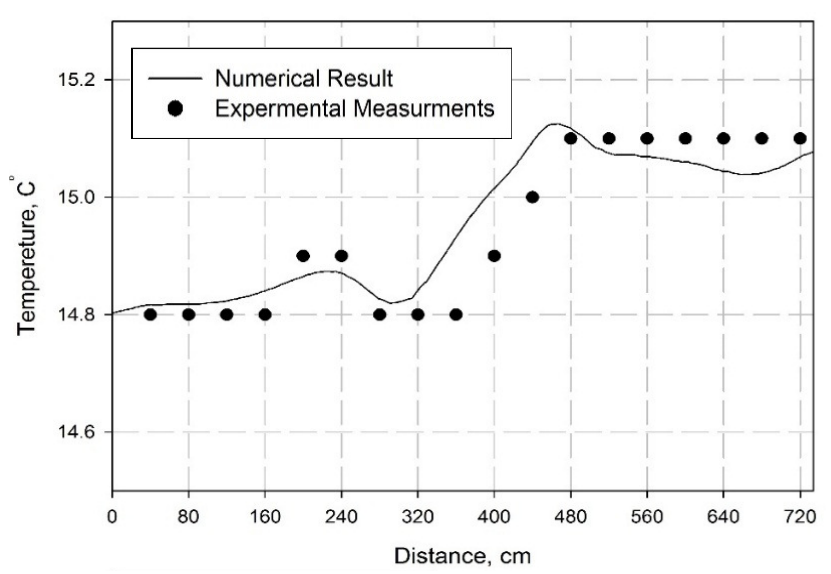

Fig. 6. The simulated temperature profile versus the experimental measurements. 


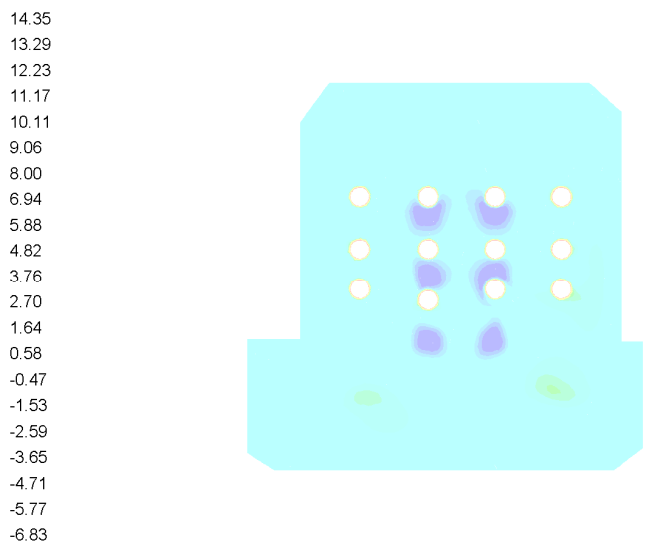

(a) Case 1
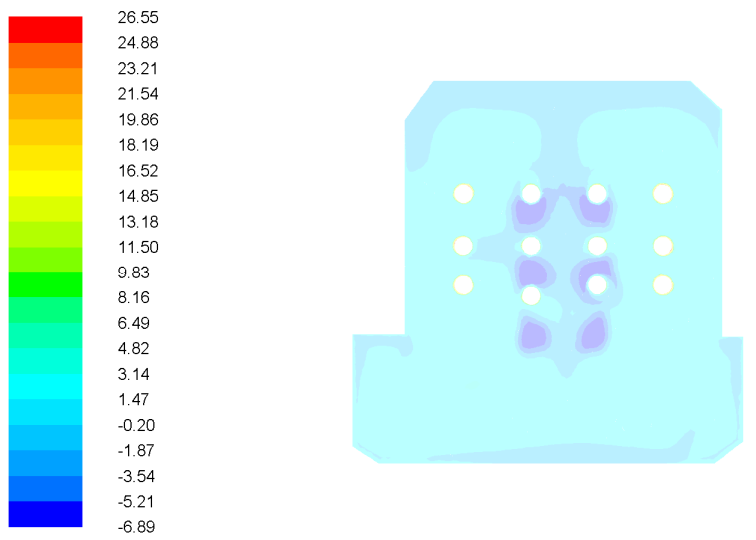

(c) Case 3

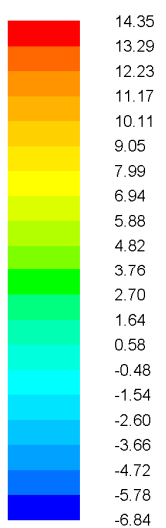

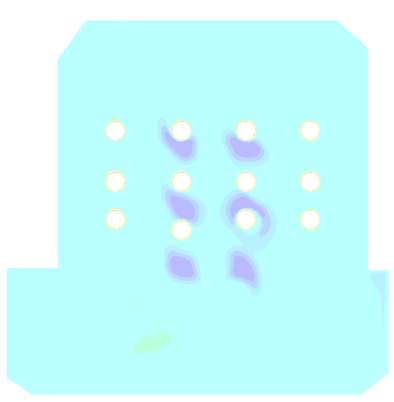

(e) Case 5 (b) Case 2

(d) Case 4
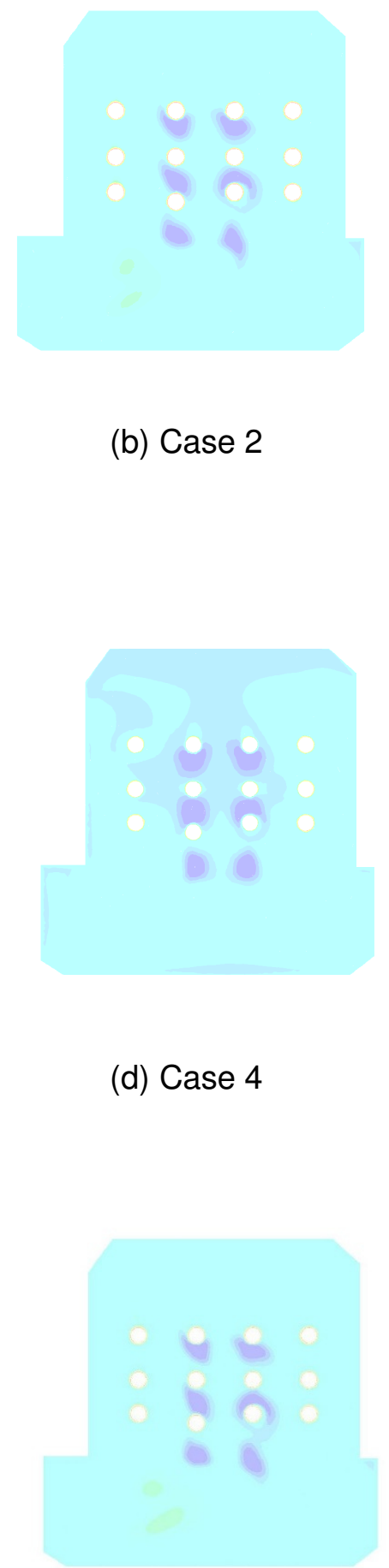

(f) Case 6

Fig. 7. Contour plots for the effective draft temperature at $z=1.6 \mathrm{~m}$. 
Table 1. Variation of the Average temperature and velocity for different mesh sizes.

\begin{tabular}{|c|c|c|c|c|}
\hline Mesh Size & $\begin{array}{c}\text { Average } \\
\text { Temperature }\end{array}$ & $\begin{array}{c}\text { percentage } \\
\text { difference in } \\
\text { Temperature }\end{array}$ & $\begin{array}{c}\text { Average } \\
\text { Velocity }\end{array}$ & $\begin{array}{c}\text { percentage } \\
\text { difference } \\
\text { in velocity }\end{array}$ \\
\hline $\begin{array}{c}\text { Fine (1.500.000 } \\
\text { elements) }\end{array}$ & 287.944284 & - & 0.08858971 & - \\
\hline $\begin{array}{c}\text { Medium (1.000.000 } \\
\text { elements) }\end{array}$ & 287.918045 & $0.009^{\mathrm{a}}$ & 0.09037046 & -2.010 \\
\hline $\begin{array}{c}\text { Coarse (500.000 } \\
\text { elements) }\end{array}$ & 287.923313 & -0.002 & 0.09600695 & -6.237 \\
\hline
\end{tabular}

a the percentage difference $=($ value for medium mesh - value for the fine mesh $) /$ value for the fine mesh \% [14]

Table 2. ADPI results in percentage $\%$.

\begin{tabular}{|c|c|c|c|c|}
\hline \multirow{2}{*}{ Case No. } & \multicolumn{3}{|c|}{ ADPI } & \multirow{2}{*}{ Average } \\
\cline { 2 - 4 } & Level 1.2 & Level 1.4 & Level 1.6 & \\
\hline 1 & 58.2 & 61.86 & 69.07 & 63.06 \\
\hline 2 & 42.9 & 48.45 & 53.61 & 48.31 \\
\hline 3 & 48.4 & 54.64 & 62.89 & 55.29 \\
\hline 4 & 38.5 & 43.30 & 41.24 & 41.00 \\
\hline 5 & 39.6 & 48.45 & 48.45 & 45.49 \\
\hline 6 & 49.5 & 53.61 & 57.73 & 53.60 \\
\hline
\end{tabular}

